\title{
Erythromycin-resistant group $G$ streptococci in an isolated northern Canadian community
}

\author{
LINDSAY NICOLLE, MD, BRIAN POSTL, MD, BARBARA URIAS, \\ BARBARA LAW, MD, NORMA LING, BSCN, ANDROULLA EFSTRATIOU,MD
}

\begin{abstract}
The susceptibility of groups A, C, and G streptococci isolated from pharynx or skin in two northern Canadian native communities during a one year study of the epidemiology of streptococcal infection was determined for penicillin, erythromycin and clindamycin using an agar dilution method. Organisms studied included 725 group A, 82 group C. and 184 group G streptococci. All organisms were susceptible to penicillin (minimum inhibitory concentration [MIC] range less than 0.004 to $0.015 \mu \mathrm{g} / \mathrm{mL}$ : MIC90 0.015 $\mu \mathrm{g} / \mathrm{mL}$ ) and clindamycin (range 0.007 to $0.06 \mu \mathrm{g} / \mathrm{mL}$; MIC90 $0.06 \mu \mathrm{g} / \mathrm{mL}$ ) with no differences observed between streptococcal groups. For erythromycin, groups $\mathrm{A}$ and $\mathrm{C}$ were generally susceptible (range less than 0.007 to $0.030 \mu \mathrm{g} / \mathrm{mL}$; $\mathrm{MIC} 900.03 \mu \mathrm{g} / \mathrm{mL}$; and range 0.007 to $1.0 \mu \mathrm{g} / \mathrm{mL}$; MIC90 $0.06 \mu \mathrm{g} / \mathrm{mL}$, respectively).
\end{abstract}

Group G was less susceptible (range 0.007 to greater than $2.0 \mu \mathrm{g} / \mathrm{mL}$; MIC90 greater than $2.0 \mu \mathrm{g} / \mathrm{mL}$ ) with $38 \%$ of all isolates having an MIC greater than or equal to $1 \mu \mathrm{g} / \mathrm{mL}$. On review of group $\mathrm{G}$ isolates, 100 of 100 from one community were susceptible (MIC less than 0.007 to $0.03 \mu \mathrm{g} / \mathrm{mL}$ ) and $73(87 \%)$ of 84 from the second community were resistant. All resistant strains tested were type T16. These data suggest that erythromycin-resistant group G streptococci may occur with high prevalence in certain populations and that patterns of antimicrobial susceptibility in isolated communities may be highly community-specific. Can $J$ Infect Dis $1990 ; 1(1): 3-6$

Key Words: Antimicrobial resistance. Erythromycin, Group G streptococci, Native health
Section of Infectious Diseases. Department of Medicine: Northern Medical Unit, Department of Community Health Sciences: Departments of Pediatrics and Medical Microbiology. Uniwersity of Manitoba; and Public Health Laboratory Service, London, UK Correspondence and reprints: Dr LE Nicolle, Health Sciences Centre, MS675D - 820 Sherbrook Street, Winnipeg. Manitoba R3A 1R9. Telephone (204) 787-4655

Received for publication January 8, 1990. Accepted February 13, 1990 casionally identified (1-3). These organisms are more frequently tolerant of antibiotics than other beta-hemolytic streptococci $(4,5)$, and plasmidmediated resistance to erythromycin has been described (6). Erythromycin resistance among group A streptococci is well documented $(3,7,8)$, and in previous reports, a high prevalence of erythromycin-resistant group A streptococci has been reported in certain geographic areas (7). In this report the antimicrobial susceptibilities of beta-hemolytic streptococci are described in two isolated northern Canadian communities, one of which had a high prevalence of group G streptococci resistant to erythromycin. 


\section{MATERIALS AND METHODS}

Study populations: A prospective study of group A streptococcal carriage and disease was undertaken in two northern Canadian native communities from November 1984 to October 1985 (9). The communities were one Inuit and one native Indian community, both with populations of approximately 1200 . Both communities are geographically isolated in northern Canada with convenient access by air only. The study design included three prevalence surveys of pharyngeal beta-hemolytic streptococcal carriage in school children in November 1984 and February and May 1985, and a prospective study of the incidence of group A streptococcal pharyngitis and impetigo with pharyngeal and skin swabs from symptomatic residents throughout the study year.

Microbiologic methods: Pharyngeal and skin swabs were inoculated and incubated, and organisms were isolated and identified in the community for the prevalence surveys. For the incidence study, specimens were forwarded by air to the study centre in Winnipeg. Manitoba for processing. All specimens were inoculated onto Mueller-Hinton agar layered with sheep blood agar and incubated overnight at $37^{\circ} \mathrm{C}$ in room air. Gram-positive, catalase-negative cocci producing beta-hemolytic colonies were presumptively identified as beta-hemolytic streptococci. Initial grouping of streptococci was done using a CAMP plate with a bacitracin A and SXT disc, and subsequently confirmed using the Streptex Latex Kit (Wellcome Diagnostics). T-typing of group G streptococci was performed at the Public Health Laboratory in London, England using previously described methods (10).

Antimicrobial susceptibility testing used an agar dilution method (11). Mueller-Hinton agar was supplemented with $5 \%$ defibrinated sheep blood agar. Organisms were grown overnight in Todd Hewitt broth and diluted to $10^{8}$ colony forming units (cfu) $/ \mathrm{mL}$ in Mueller-Hinton broth using a McFarland standard. A 1:10 dilution in broth to $10^{7} \mathrm{cfu} / \mathrm{mL}$ was made, and $10^{4} \mathrm{cfu} / \mathrm{mL}$ was applied with a Steers replicator to blood agar plates of twofold increasing antibiotic concentration. Plates were examined after $24 \mathrm{~h}$ of incubation at $37^{\circ} \mathrm{C}$ in room air. The minimal inhibitory concentration (MIC) was the lowest antimicrobial concentration which prevented any growth of the organism.

\section{RESULTS}

A total of 725 group A, 82 group C and 184 group G streptococci were isolated. The MICs of the three beta-hemolytic streptococci to penicillin $\mathrm{G}$, erythromycin, and clindamycin are shown in Figure 1. The MICs were generally comparable for penicillin and clindamycin. For erythromycin, groups $\mathrm{A}$ and $\mathrm{C}$ streptococci had comparable MICs, but group G streptococci demonstrated a biphasic distribution.

The group G streptococci with elevated MICs were all isolated from residents of the native Indian community (Figure 2). All isolates of group G streptococci from the Inuit community were susceptible to erythromycin, whereas $86 \%$ of isolates from the native Indian community had MICs of at least $1 \mu \mathrm{g} / \mathrm{mL}$. The MICs of group G streptococci for the three prevalence surveys in the native Indian community were greater than or equal to 1 $\mu \mathrm{g} / \mathrm{mL}$ for 24 of $29(83 \%)$ isolates at the first survey, 21 of $22(95 \%)$ at the second survey and 16 of 16 at the third survey. Thus, the proportion of group G streptococci with elevated MICs increased consecutively throughout the study

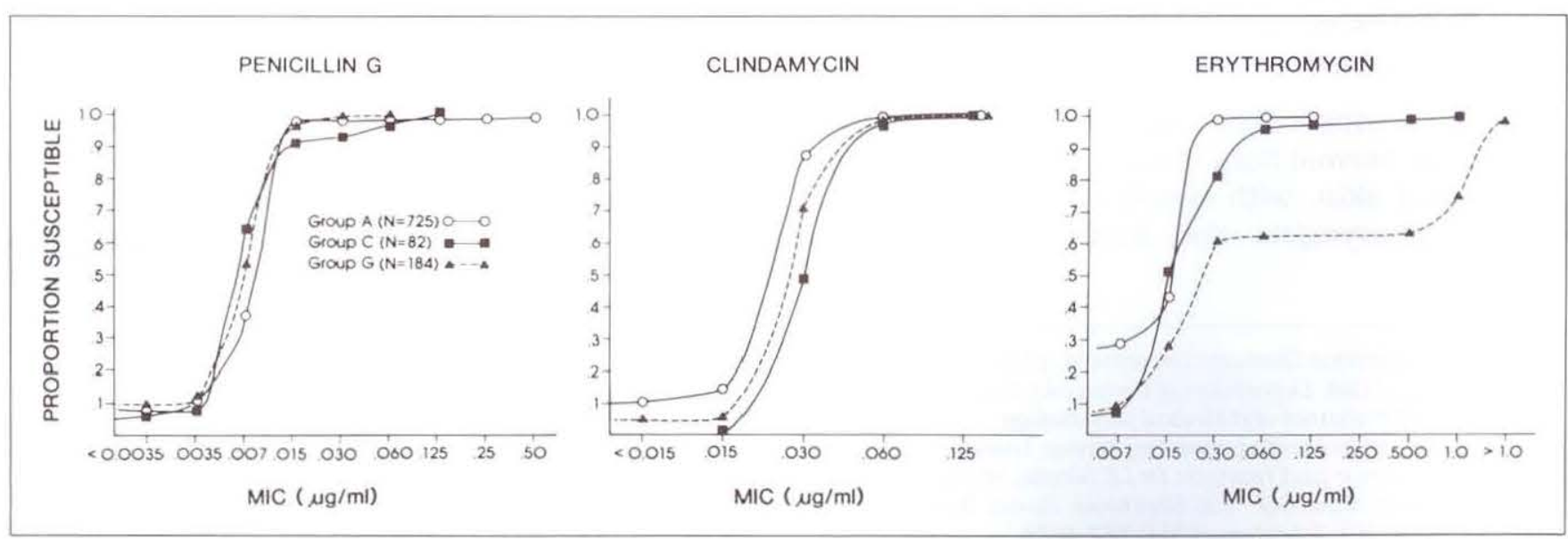

Figure 1) Minimal inhibitory concentrations of groups A, C and G beta-hemolytic streptococci isolated in two northern Canadian communities to penicillin $G$, erythromycin and clindamycin 


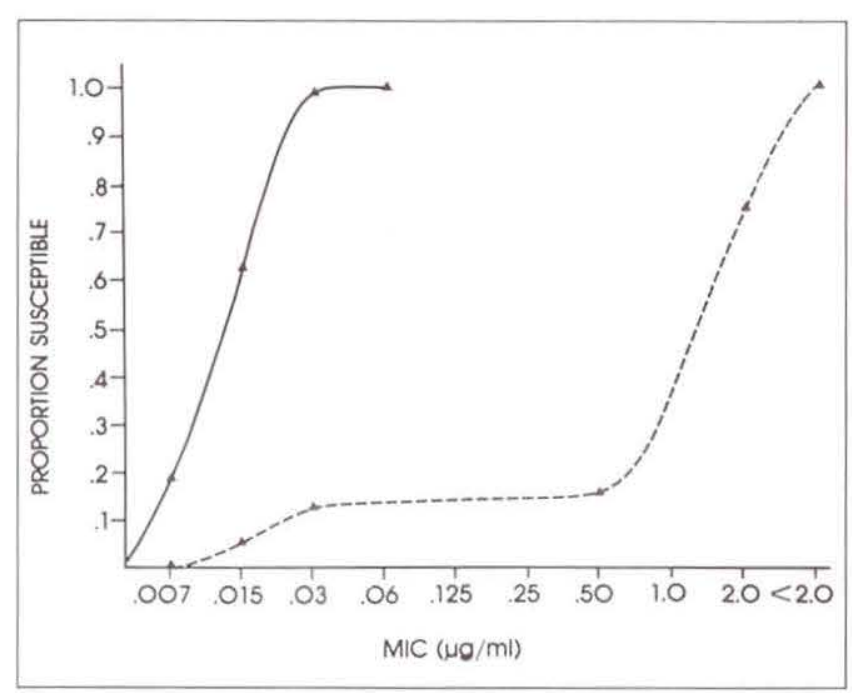

Figure 2) Minimal inhibitory concentrations of erythromycin for group $G$ streptococci in two northern communities, one Inuit (solid line) and the other native Indian (dashed line)

period. Twelve $(71 \%)$ of 17 group G streptococci isolated from symptomatic individuals between surveys had MICs greater than or equal to $1 \mu \mathrm{g} / \mathrm{mL}$.

The prevalences of group G streptococci in the native Indian school population, mostly asymptomatic, for the three prevalence surveys were $7.0,5.9$ and $4.8 \%$. The prevalence from pharyngeal swabs obtained for the incidence survey from symptomatic school children was 3.1\%, and for symptomatic adults and children below school age, $5.0 \%$. Thus there was no apparent association of group G streptococci with symptoms, suggesting that the erythromycin-resistant group G streptococci were unlikely to be contributing to pharyngeal disease in the community.

T-typing was performed on a subset of 59 of the group G streptococci. These included 29 susceptible strains - nine from the native Indian community and 20 from the Inuit - and 30 resistant strains. All 30 erythromycin-resistant strains were T16. Only two of 20 strains from the Inuit community could be typed with available antisera; one was T303 and one T305. Of the nine susceptible strains from the Indian community, four were T16, two T7, one each T305/307 and $\mathrm{T} 7 / 302$, and one nontypeable.

Information documenting erythromycin use in the two communities was not available. However, all antibiotics given in the two communities are dispensed through the nursing station. Erythromycin ordered for the nursing station in the Inuit community was 120 100-tablet (250 mg) bottles. and $400100-\mathrm{mL}(40 \mathrm{mg} / \mathrm{mL})$ bottles of suspension for 1985. For the native Indian community erythromycin acquisition was not available for
1985, but 150 100-tablet ( $250 \mathrm{mg}$ ) bottles, 200 bottles of suspension and 10 injectables were ordered for 1987.

\section{DISCUSSION}

In the observation period a high proportion of isolates of group G streptococci resistant to erythromycin were documented in one of two geographically isolated northern communities surveyed. This high population prevalence of erythromycin resistance in group G streptococci has not, to the authors' knowledge, been previously reported, although erythromycin resistance is well described in some clinical isolates (7). Erythromycin resistance was not observed in groups A or C streptococci. All resistant streptococci were of the same T-type, suggesting widespread dissemination of a single strain rather than a resistance determinant. This is consistent with observations for group A streptococci in which, when a high prevalence of erythromycin resistance has been observed, the resistant strains have been of the same serotype $(1,7,8)$.

While the high prevalence of erythromycin-resistant streptococci in the native Indian community is striking, no resistant group G streptococci were identified in the Inuit community. The Inuit community is as isolated as the native Indian community, and erythromycin use between the two communities as evidenced by antibiotic orders appeared similar. During this same study year a significantly higher prevalence and incidence of group A streptococcal disease was observed in the Inuit community, and the pharyngeal carriage of group G streptococci was inversely proportional to that of group A streptococci in both communities (9). It is possible that the low prevalence of group A streptococci in the native Indian community may have been one factor facilitating dissemination of the group G streptococcus. However, a determination of what organism or community factors contributed to the emergence and widespread dissemination of this strain requires further investigation.

In a previous study of chemoprophylaxis for meningococcal meningitis in an isolated northern Inuit community the authors documented the rapid emergence and persistence of rifampinresistant Haemophilus influenzae following community-wide rifampin use (12). In this study a high prevalence of erythromycin-resistant group $\mathrm{G}$ streptococci with increasing prevalence of the strain throughout the study year was observed in one closed population. These studies suggest that patterns of antimicrobial susceptibility in these communities may be highly community-specific, likely reflecting varying patterns of antimicrobial 
use as well as other factors not yet defined. These small, geographically isolated communities may serve as models for exploring parameters which promote the emergence and transmission of resistant organisms in non-institutionalized populations.

ACKNOWLEDGEMENTS: Dr Nicolle was a member of the Departments of Medicine and Microbiology and Infectious Diseases, University of Calgary when this study was performed. This study was funded by a grant from the National Health Research and Development Fund. Hattie Subgut and Georgina Wood were community workers. Expert secretarial assistance was provided by B Kowalczyk.

\section{REFERENCES}

1. Lam K. Bayer AS. Serious infections due to group G streptococci. Report of 15 cases with in vitroin vivo correlations. Am J Med 1983:75:561-70.

2. Gaunt PN, Seal DV. Group G streptococcal infections. J Infect 1987:15:5-20.

3. Istre GR, Welch DF, Marks MI, Moyer N. Susceptibility of group A beta-hemolytic streptococci isolates to penicillin and erythromycin. Antimicrob Agents Chemother 1981:20:244-6.

4. Noble JT, Tyburski MB, Berman M, Greenspan J.
Tenenbaum MJ. Antimicrobial tolerance in group G streptococci. Lancet 1980:ii:982.

5. Rolston KVI, Chandrasehar PH, Le Froch JL. Antimicrobial tolerance in group $\mathrm{C}$ and group $\mathrm{G}$ streptococci. J Antimicrob Chemother 1984:13:389-92.

6. Bougueleret L, Beeth G, Horodnicianu T. Conjugative $\mathrm{R}$ plasmids in group $\mathrm{C}$ and $\mathrm{G}$ streptococci. J Bacteriol 1981;145:1 102-5.

7. Dixon JMS, Lipinski AE. Resistance of group A beta-hemolytic streptococci to lincomycin and erythromycin. Antimicrob Agents Chemother 1972:1:333-9.

8. Maruyama S, Yoshioka H, Fujita K, Takimoto M. Satahe Y. Sensitivity of group A streptococci to antibiotics. Am J Dis Child 1979:133:1143-5.

9. Nicolle LE, Postl B. Urias B, Law B, Ling N, Dixon JMS. Group A streptococcal pharyngeal carriage. pharyngitis, and impetigo in two northern Canadian native communities. Clin Invest Med. (In press)

10. Efstratiou A. The serotyping of hospital strains of streptococci belonging to Lancefield group C and group G. J Hyg [Camb] 1983:90:71-80.

11. Eliopoulos GM, Gardella A, Moellering RC Jr. In vitro activity of ciprofloxacin, a new carboxyquinolone antimicrobial agent. Antimicrob Agents Chemother 1984:25:331-5.

12. Nicolle LE. Postl B, Kotelewetz E, et al. Emergence of rifampin resistant Haemophilus influenzae. Antimicrob Agents Chemother 1982:21:498-500. 


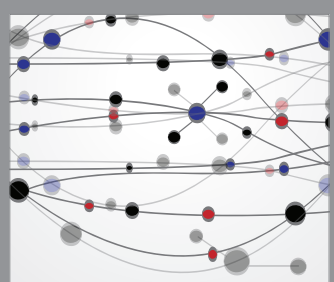

The Scientific World Journal
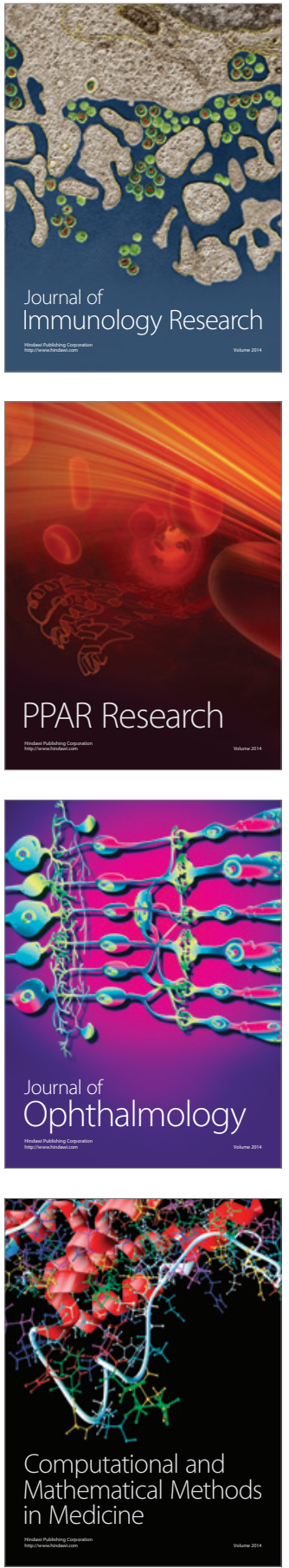

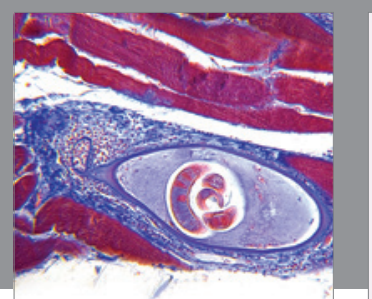

Gastroenterology Research and Practice

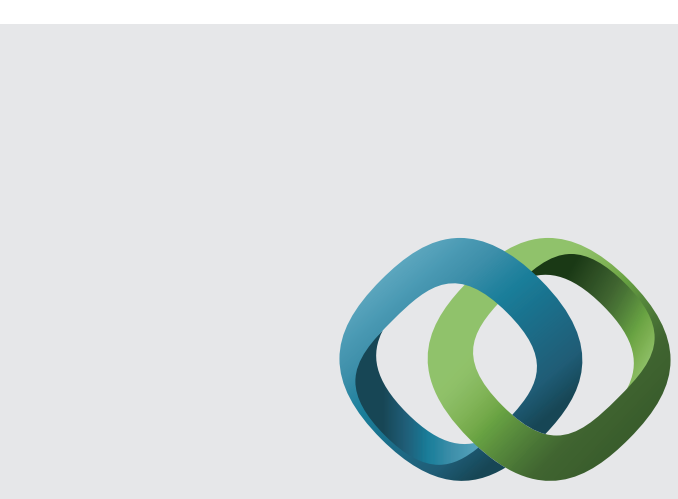

\section{Hindawi}

Submit your manuscripts at

http://www.hindawi.com
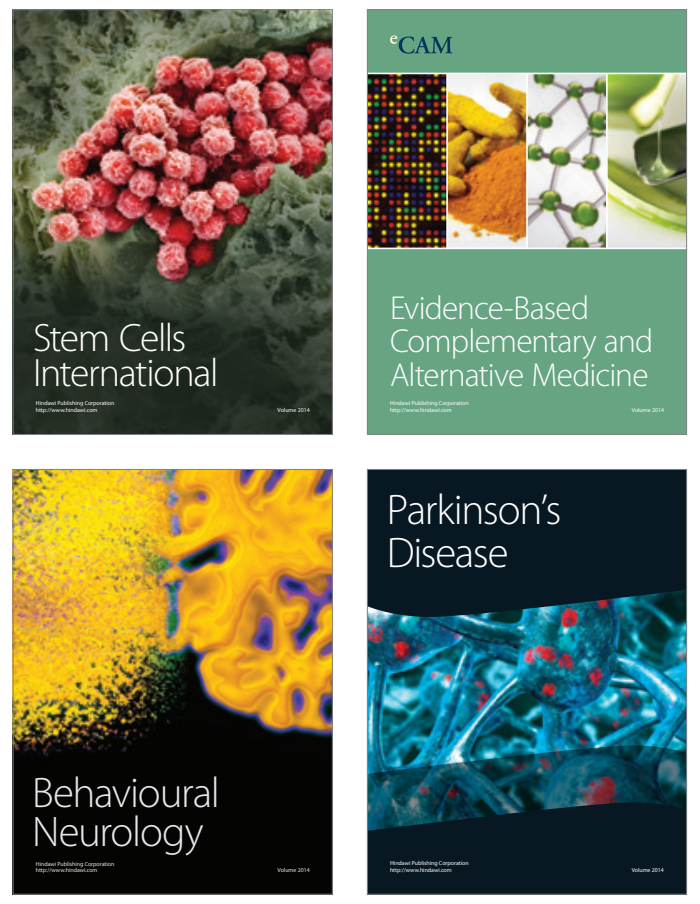
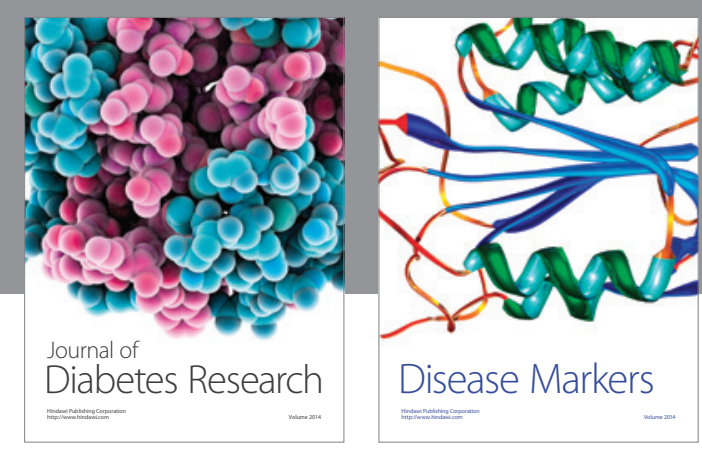

Disease Markers
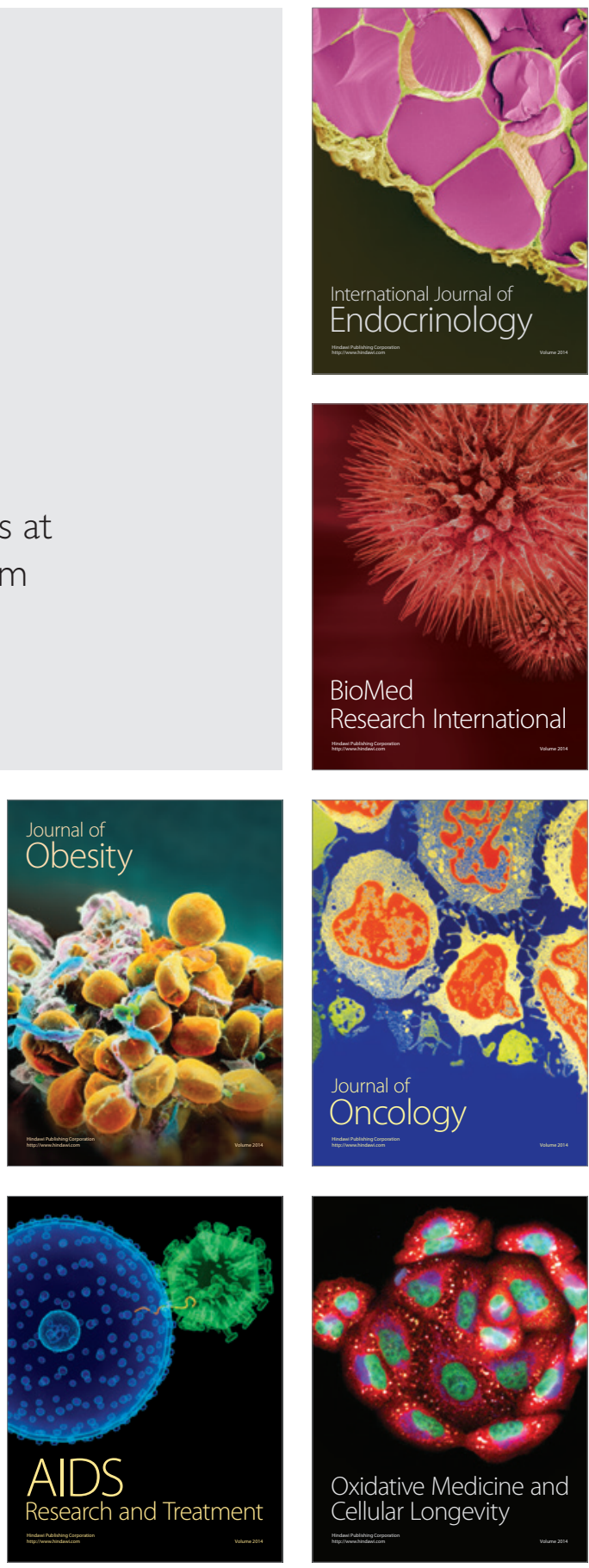